\title{
LC-MS/MS METHOD FOR THE TRACE LEVEL DETERMINATION OF ETHYL BENZENE SULFONATE: A GENOTOXIC IMPURITY IN AMLODIPINE BESYLATE
}

\author{
Sumanth Mullangi and Kunta Ravindhranath* \\ Department of Chemistry, Koneru Lakshmaiah Education Foundation, Green Fields, \\ Vaddeswaram-522 502, Guntur Dt., A.P., India \\ *E-mail: ravindhranath.kunta@gmail.com
}

\begin{abstract}
A highly sensitive method for the quantification of genotoxic impurity Ethylbenzene sulfonate (EBS) in Amlodipine Besylate using hyphenated techniques, has been developed. EBS is assessed by LC-MS/MS-SIM mode method using Inertsil ODS $3 \mathrm{~V}(150 \times 4.6 \mathrm{~mm}) 3.0 \mu \mathrm{m}$ column. $0.01 \mathrm{M} \mathrm{CH}_{3} \mathrm{COONH}_{4}$ is used as a buffer and its admixture with $\mathrm{CH}_{3} \mathrm{CN}$ in the ratios: 60:40 and 5:95 v/v, are found to be effective mobile phase-A and mobile phase B respectively. The gradient program (Time, minutes $/ \% \mathrm{~B}, \mathrm{v} / \mathrm{v}$ ) is fixed as $0 / 5,2.5 / 5,5.0 / 50,10.0 / 70,15.0 / 95,20.0 / 95$ and $24.0 / 5$. Validation of the method developed is assessed as per recommendations of the International Conference on Harmonization. LOD and LOQ values of EBS are 0.01 and $0.04 \mu \mathrm{g} / \mathrm{mL}$ respectively. The method has accuracy within $98.1-103.0 \%$ for the analyte. This method is direct, convenient, accurate and cost-effective and it can be adopted as quality control means for the determination of EBS in Amlodipine Besylate
\end{abstract}

Keywords: Amlodipine Besylate, Ethylbenzene Sulfonate (EBS), Genotoxic, Selected Ion Monitoring (SIM)

(C) RASĀYAN. All rights reserved

\section{INTRODUCTION}

Amlodipine besylate is chemically known as 3-Ethyl 5-methyl (4RS)-2-[(2-aminoethoxy) methyl]-4-(2chlorophenyl)-6-methyl-1,4-dihydropyridine-3,5-dicarboxylate benzene sulfonate, indicated in hypertension therapy and mechanistically classified under calcium channel blockers (CCBs). ${ }^{1}$ Although Amlodipine molecule is having chirality and exists as a racemic mixture, only (-)-(S)- enantiomer is known to have CCB effect. ${ }^{2,3}$ Amlodipine is one of the inherently long-acting and vasoselective drug which shows a great effect on the smooth muscle cells of the vascular component rather than the muscle cells of heart, it selectively influxes calcium ions across membrane cells due to the presence of key calcium antagonist dihydropyridine(DHP). Impurities in the Drug substances are prone to generate from the reagents, starting materials that are employed in the synthetic process and also from the synthetic byproducts formed during the process. Some of these impurities are mutagenic or carcinogenic and hence elimination of these genotoxic impurities in the final drug product is considered as critical and essential. ${ }^{4}$ Several modifications in the process are employed to reduce the levels of these impurities. Complete elimination of these impurities from drug substance is not possible. Control of these impurities levels based on the daily dose is critical as per the guidelines of regulatory authorities. ${ }^{5,6}$ Sulfonic acid esters fall under PGIs (potentially genotoxic impurities) category in pharmaceuticals. Ester of sulfonic acid arise and carry to final drug substance from any stage of synthesis and/or during the crystallization of the salt which utilizes the alcohol. Ethylbenzene sulfonate (EBS) is such a kind of impurity that has been characterized as potentially genotoxic and it has the intake limit of $1.5 \mu \mathrm{g} /$ day as per the regulatory. PGIs are known for their genetic mutations and aberrations in chromosomes and are reported in mice and rats as potential carcinogens ${ }^{7}$. The regulatory agencies have a special focus on genotoxic impurities presence in medicinal products. A European regulatory agency which is called as "European Medicines Agency (EMEA)", has appointed a committee to provide guidelines for the limits of genotoxic impurities in Medicinal products for Human use (CHMP) ${ }^{8}$. Later in the year 2008, the United States Food and Drug Administration 
(USFDA) also published draft guidelines for both drug substances and drug products on genotoxic impurities. These guidelines will help in reducing the potential lifetime risk of cancer upon exposure of patients to carcinogenic and genotoxic impurities present in pharmaceutical products. To suffice the current regulatory requirements with the allowed intake of individual genotoxic impurity at $1.5 \mu \mathrm{g} / \mathrm{day}$, highly sensitive analytical methods should be developed..$^{9,10}$ Available research work is not sensitive enough to detect genotoxic impurities in such trace levels. ${ }^{11}$

Following the amplifying concerns of regulatory authorities regarding the control of these PGIs in pharmaceuticals products, an attempt has been made in the present investigation to develop an improved and highly sensitive method using LC-MS/MS to determine the Ethylbenzene sulfonate at very low levels in Amlodipine besylate.

\section{EXPERIMENITAL}

\section{Material}

Ethyl Benzene Sulfonate (EBS) was obtained from Sigma-Aldrich, Bangalore, India. Ammonium acetate (AR) and methanol (HPLC-grade) were procured from Merck\& Co, India. Amlodipine Besylate was obtained from Mylan Labs Ltd. Hyderabad.

\section{Chromatographic Conditions}

Shimadzu LCMS 8040 system was employed for chromatography and separation was done using Inertsil ODS 3V $(150 \times 4.6) \mathrm{mm}, 3.0 \mu \mathrm{m}$ analytical column. Gradient mode of elution was performed using $0.01 \mathrm{M}$ $\mathrm{CH}_{3} \mathrm{COONH}_{4}$ as buffer and $\mathrm{CH}_{3} \mathrm{CN}$ as a solvent in different ratios for mobile phases $\mathrm{A}$ and $\mathrm{B}$. Mobile phases A consists of $0.01 \mathrm{M} \mathrm{CH}_{3} \mathrm{COONH}_{4}$ buffer: $\mathrm{CH}_{3} \mathrm{CN}$ in $60: 40(\mathrm{v} / \mathrm{v})$ ratio and mobile phase $\mathrm{B}$ composed of buffer and $\mathrm{CH}_{3} \mathrm{CN}$ in 5:95 (v/v) ratio. The gradient program (Time, minutes/\%B, v/v) was set as $0 / 5,2.50 / 5,5.0 / 50,10.0 / 70,15.0 / 95,20.0 / 95$ and $24.0 / 5$. The flow rate of $1.0 \mathrm{~mL} / \mathrm{min}$ was maintained throughout the chromatographic separation. Temperatures of column oven and autosampler were maintained at $30^{\circ} \mathrm{C}$ and $25^{\circ} \mathrm{C}$ respectively and the injection volume was fixed as $20 \mu \mathrm{L}$. Instrument control, data acquisition and data processing were done by LCMS Lab Solutions software.

\section{Operational Conditions of Mass Spectrometer}

Typical operation settings were as follows: capillary voltage: $3.0 \mathrm{KV}$; sample cone voltage: $30 \mathrm{v}$; the temperature of source: $120^{\circ} \mathrm{C}$; desolvation temperature: $350^{\circ} \mathrm{C}$; cone gas flow rate: $50 \mathrm{Lit} / \mathrm{Hr}$; desolvation gas: Nitrogen; and argon as CID gas for MS/MS experimentation. The selective ion monitoring (SIM) was selected for quantification of EBS. Valco valve was used to drain the undesired Amlodipine peak from $6.1 \mathrm{~min}$ to $15.0 \mathrm{~min}$.

\section{Standard Solution Preparation}

The concentrated stock of $0.5 \mathrm{mg} / \mathrm{mL}$ was prepared by dissolving $5 \mathrm{mg}$ of EBS in $10 \mathrm{ml}$ of acetonitrile. Further, $1.0 \mathrm{~mL}$ of concentrated stock solution $(0.5 \mathrm{mg} / \mathrm{mL})$ was diluted to $50 \mathrm{~mL}$ with $\mathrm{CH}_{3} \mathrm{CN}$ to get diluted stock solution having concentration of $0.01 \mathrm{mg} / \mathrm{mL}$. Final working level standard solution with $0.05 \mu \mathrm{g} / \mathrm{mL}$ was prepared by diluting $1.0 \mathrm{~mL}$ of diluted stock solution $(0.01 \mathrm{mg} / \mathrm{mL})$ to $200 \mathrm{~mL}$ volume with diluent, water: $\mathrm{CH}_{3} \mathrm{CN}$ 50:50(v/v).

\section{Sample Preparation}

Amlodipine Besylate sample of concentration: $10 \mathrm{mg} / \mathrm{ml}$, was prepared by dissolving $10 \mathrm{mg}$ of accurately weighed drug substance in $1 \mathrm{ml}$ of diluent-water: $\mathrm{CH}_{3} \mathrm{CN}(50: 50 \mathrm{v} / \mathrm{v})$, in an HPLC vial and injected immediately into the chromatographic system.

\section{Validation Study}

According to the ICH validation guidelines, the method developed for the trace level determination of EBS in Amlodipine besylate was validated. Major validation parameters were addressed in the study. The linearity of the method was established by the analysis of six different concentrations from the specification limit of $0.05 \mu \mathrm{g} / \mathrm{mL}$ to $0.20 \mu \mathrm{g} / \mathrm{mL}$ for EBS. Linear regression least square analysis was used to establish intercept, slope, and regression coefficient. Six replicate injections of the standard solution 
RASĀYAN J. Chem.

Vol. 13 | No. 3 |1662-1671| July - September | 2020

were injected to demonstrate the mass spectroscopic system precision. By displaying precision with the injection of lower concentrations of EBS in six replications, the LOD and LOQ values were determined. LOQ level was determined from the lowest concentration of EBS that produced $\mathrm{S} / \mathrm{N}$ ratio 10 and \%RSD $<10$. LOD was established from the lowest level concentration of EBS that shows $\mathrm{S} / \mathrm{N}$ ratio 3. \% RSD was calculated from spiked analyte sample to show method precision. Accuracy of the method was determined from six different sample preparations spiked with a known concentration of analyte (EBS). The solution stability of the spiked sample was proven by storing the solutions at room temperature at different intervals of time.

\section{Sample Preparation and its Optimization}

\section{RESULTS AND DISCUSSION}

In genotoxic impurities (GTI) analyses, sample preparation is a key exercise that influences analyte stability, sensitivity, recovery, and matrix effect in trace analysis. Various diluents were tried to evaluate the matrix recovery efficiency and the response of chromatographic peak. Acetonitrile was found to have good solubilization capacity for both the drug substance and analyte, EBS. Because of lower response for the analytes and improper peak shapes observed with acetonitrile alone, in the chromatographic separation, acetonitrile alone was not suitable. So different ratios of acetonitrile and water were evaluated. Good response, proper peak shapes and good recovery values were observed for the analyte EBS with the premixed solution of 50:50 (v/v) acetonitrile/water.

\section{Column Selection and Separation}

Owing to the peak broadening that results from the high concentration of the sample, achieving a proper resolution between the analyte and sample is a crucial part of genotoxic impurities trace analysis. Numerous kinds of chromatographic columns were utilized to achieve the appropriate resolution of the analyte and drug substance peaks. Various columns like Zorbax Rx C18, Inertsil ODS 3V and Kromasil $\mathrm{C} 18$ with different column dimensions were screened. Based on the less response and low resolution of analytes with the sample peak, it was found that the columns Zorbax Rx C18 and Kromasil C18 were not suitable. Good response and separation were displayed on Inertsil ODS $3 \mathrm{~V}$ column of dimensions $150 \mathrm{~mm}$ $\mathrm{x} 4.6 \mathrm{~mm} \times 3.0 \mu \mathrm{m}$ for EBS. The analyte EBS was retained well and resourcefully separated from the peak of Amlodipine Besylate. Improved retention and better-quality peak shapes were observed due to the exceptional amalgamation of bonding and end-capping on Inertsil ODS 3V. An improved and higher sensitivity level for EBS peak is observed due to lower particle size of the analytical column used. Diverse mobile phase combinations were analyzed using premixed $0.1 \%$ acetic acid ( $\mathrm{v} / \mathrm{v}$ in water), $0.1 \%$ formic acid ( $\mathrm{v} / \mathrm{v}$ in water), and ammonium formate, with methanol and acetonitrile. Good separation and response were achieved in both the elution modes (isocratic and gradient) by using ammonium acetate buffer and acetonitrile combination. The optimum separation and response for EBS and drug substance peaks were noticed with gradient elution. To achieve accurate retention time, the flow rate and column temperature were maintained at $1 \mathrm{~mL} / \mathrm{min}$ and $30^{\circ} \mathrm{C}$ respectively. For mass spectrometric detection, the flow rate was reduced to $0.2 \mathrm{~mL} / \mathrm{min}$ with a splitter, before the electrospray ionization. EBS peak was retained about 5.5 mins. Well separated Gaussian peaks resulted in EBS from the drug peak.

The peak corresponding to Amlodipine Besylate eluted at around 14mins. Due to adequate separation of analyte and drug peaks, drug peak is vented by using a Valco valve and analyte of interest EBS is only allowed to pass through the mass detector. This venting/draining process nullified the matrix effect resulting from the high sample concentration and enhanced the detection capacity.

\section{Optimization of Mass Spectrometric Parameters}

The efficiency of the chromatographic method is a function of detection technique under process. So, the selection of the appropriate detection method in the trace-level analysis is a crucial process. Due to the insufficient sensitivity and specificity for the trace analysis of EBS with the HPLC-UV and GC-FID methods, more specific as well as sensitive tandem LC-MS/MS - technique was employed in SIM mode of detection. As SIM mode specifically detects the ions of a particular mass to charge ratio, it provides the significant enhancement of selectivity and sensitivity for the trace level determination. In positive SIM mode, EBS ion peak-mass was observed at 204.1 corresponding to $[\mathrm{M}+18]^{+}=[\mathrm{M}+\mathrm{NH} 4]^{+}$. The obtained chromatograms of LC-MS/MS SIM and fragmentation patterns of EBS are shown in Fig.-1 and 2. 
RASĀYAN J. Chem.

Vol. 13 | No. 3 |1662-1671| July - September | 2020
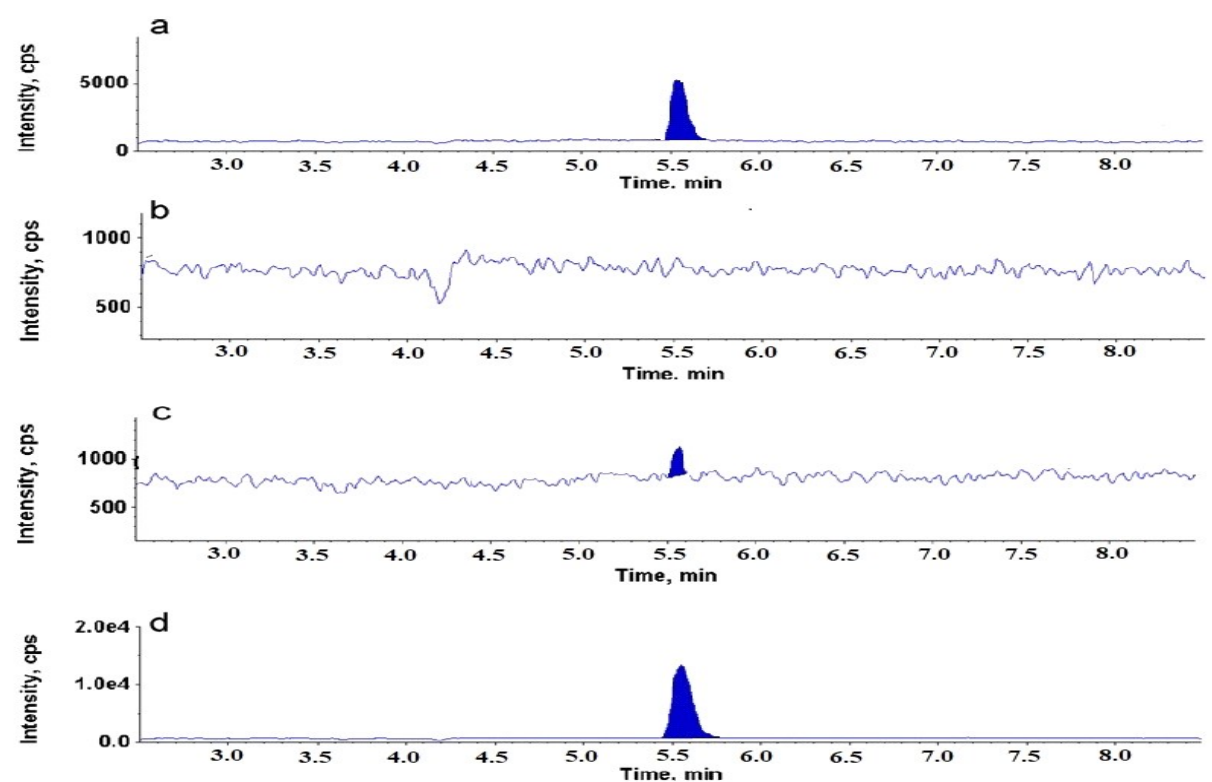

Fig.-1: EBS SIM Scan Chromatograms: (a) Standard Chromatogram of EBS at $0.05 \mu \mathrm{g} / \mathrm{mL}$ (b) Blank Chromatogram, (c) EBS in Amlodipine Besylate sample, (d) Amlodipine Besylate sample spiked with EBS at

\section{Validation of Method} $0.05 \mu \mathrm{g} / \mathrm{mL}$.

Method validation parameters such as limit of detection (LOD), limit of quantitation (LOQ), specificity, linearity, accuracy, precision, robustness were established for the trace level analysis of the EBS in amlodipine besylate. Validation data was established by following ICH guidelines and data is tabulated in below Table-1.

Table-1: Validation Data for the Determination of EBS

\begin{tabular}{c|c}
\hline Parameter & EBS \\
\hline LOD & $0.01 \mu \mathrm{g} / \mathrm{mL}$ \\
\hline LOQ & $0.04 \mu \mathrm{g} / \mathrm{mL}$ \\
\hline Precision, LOQ (RSD \%) & 1.02 \\
\hline Linearity & $0.05-0.20 \mu \mathrm{g} / \mathrm{mL}$ \\
\hline Correlation coefficient & $>0.998$ \\
\hline Accuracy at LOQ (Recovery $\%)$ & $98.1-103.0$ \\
\hline
\end{tabular}

\section{Specificity}

The specificity of the LC- MS/MS method was proven by displaying mass to charge ratio $(\mathrm{m} / \mathrm{z})$ of EBS adduct i.e. [M+NH4] as 204.1.

\section{Linearity}

The linearity of EBS was acceptably established with a six-point calibration graph ranging from $0.05 \mu \mathrm{g} /$ $\mathrm{mL}$ to $0.2 \mu \mathrm{g} / \mathrm{mL}$. The LC-MS/MS SIM chromatograms of EBS for linearity study are shown in Fig.-3. The correlation coefficient for analyte: EBS was $>0.998$ and the data are represented in Table- 2 and Fig.3 and 4.

Table-2: Linearity of Ethylbenzene Sulfonate

\begin{tabular}{c|c|c}
\hline \multirow{2}{*}{ S. No. } & \multicolumn{2}{|c}{ Ethyl Benzene Sulfonate } \\
\cline { 2 - 3 } & Concentration $\mu \mathrm{g} / \mathrm{mL}$ & Area \\
\hline 1 & 0.050 & 5631 \\
\hline 2 & 0.075 & 7754 \\
\hline 3 & 0.100 & 10585 \\
\hline
\end{tabular}


RASĀYAN J. Chem.

Vol. 13 | No. 3 |1662-1671| July - September | 2020

\begin{tabular}{c|c|c}
\hline 4 & 0.125 & 12941 \\
\hline 5 & 0.150 & 15607 \\
\hline 6 & 0.200 & 20693 \\
\hline Slope & \multicolumn{3}{|c}{101321} \\
\hline Intercept & 381.1 \\
\hline Correlation Coefficient & \multicolumn{3}{|c}{0.9993} \\
\hline
\end{tabular}

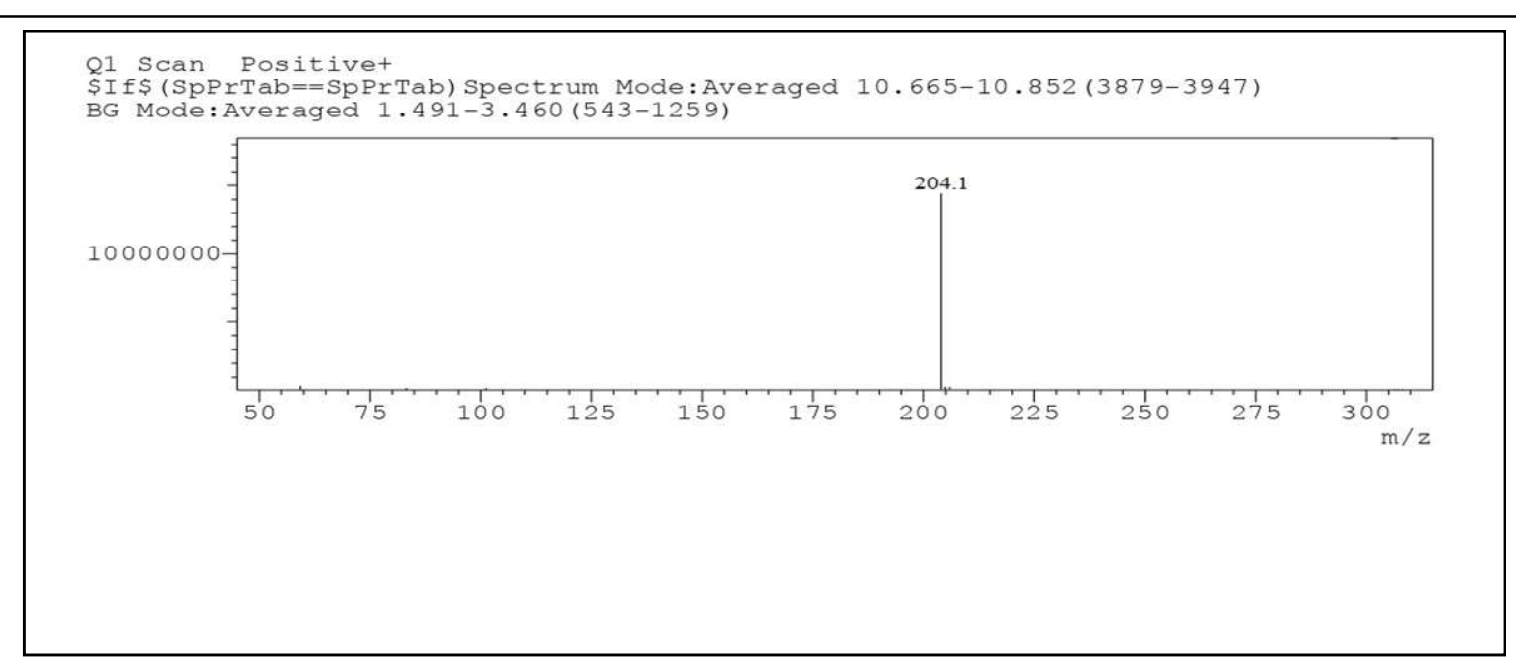

Fig.-2a: MS-MS Spectrum for EBS in SIM Mode

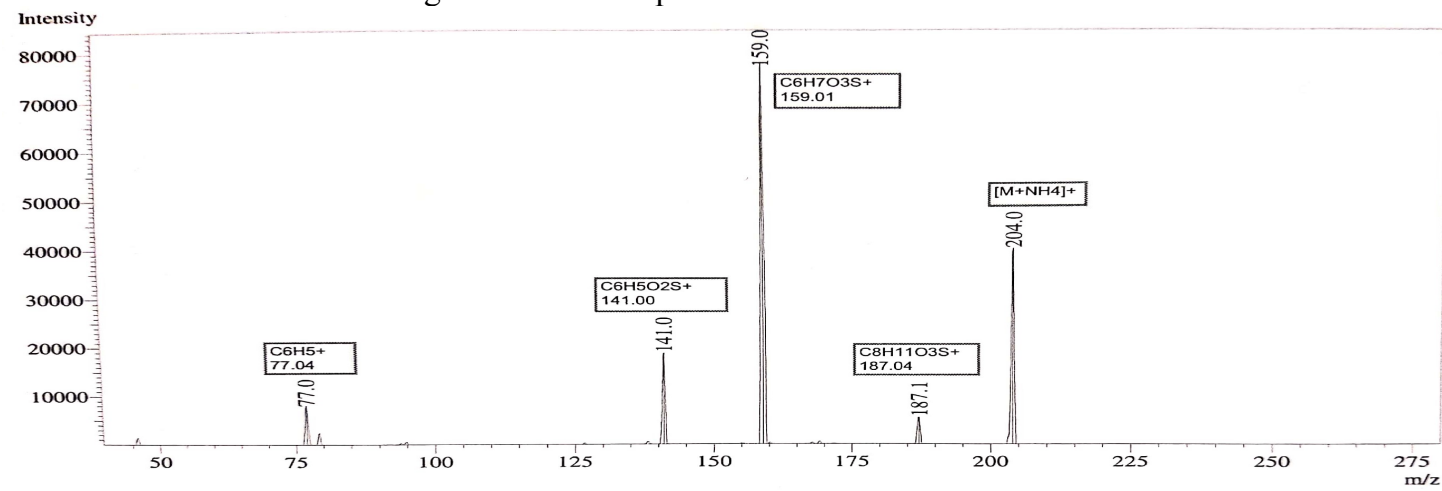

Fig.-2b: Mass Spectral Fragmentation Pattern for EBS
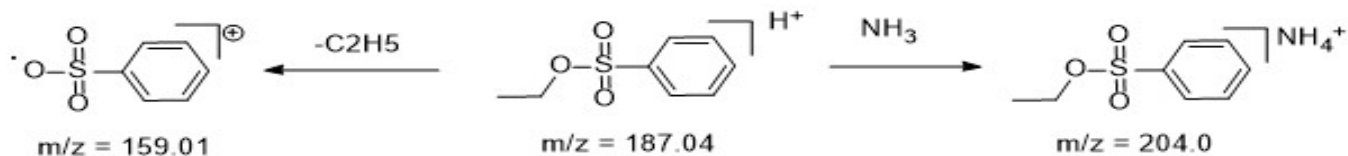

$\mathrm{m} / \mathrm{z}=159.01$

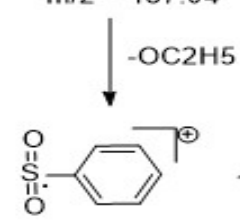

$\mathrm{m} / \mathrm{z}=204.0$

$m / z=141.00$

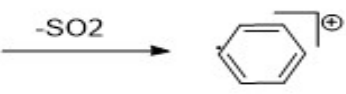

$\mathrm{m} / \mathrm{z}=77.04$

Fig.-2c: The Fragmentation Species of EBS 


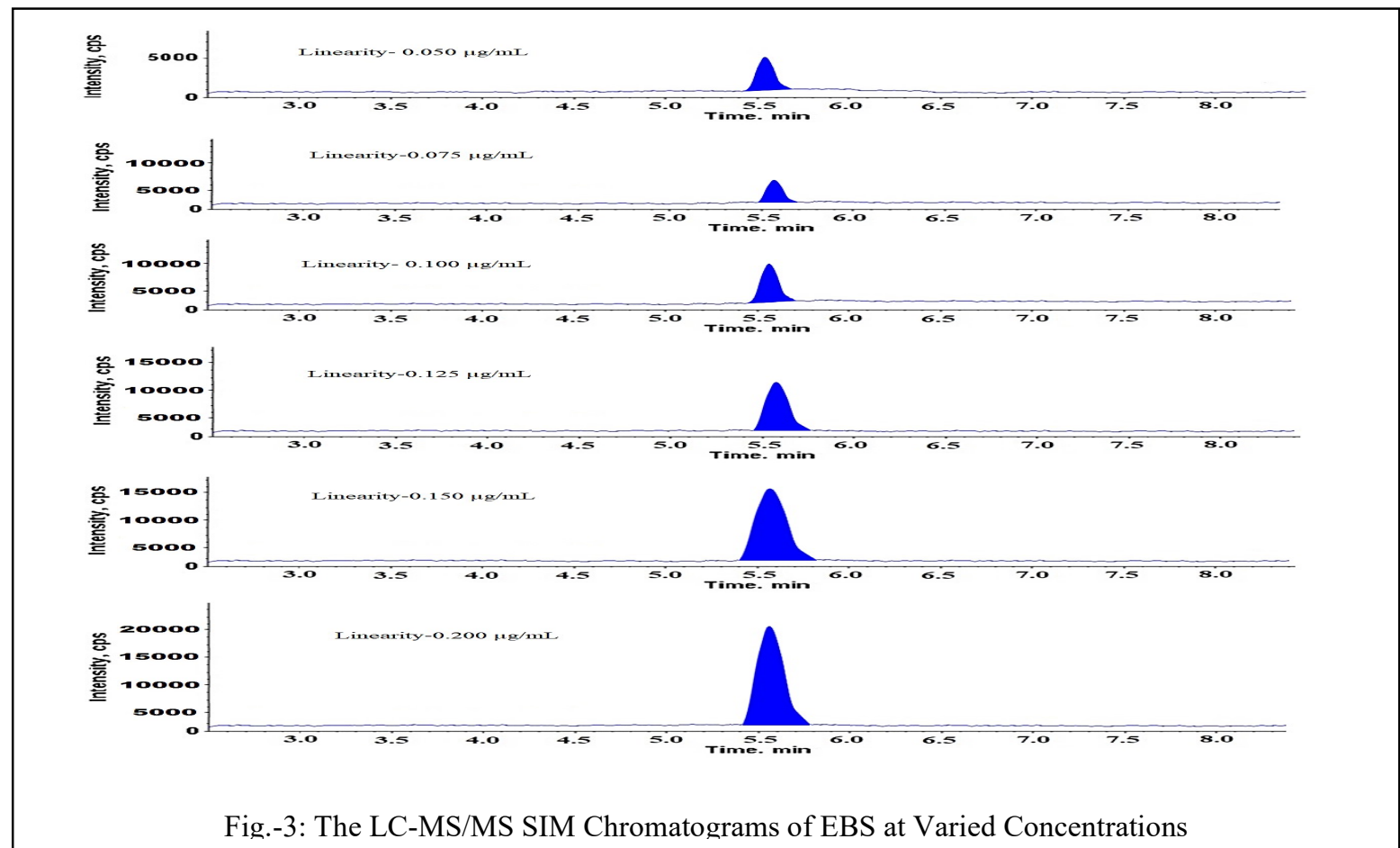

Fig.-3: The LC-MS/MS SIM Chromatograms of EBS at Varied Concentrations

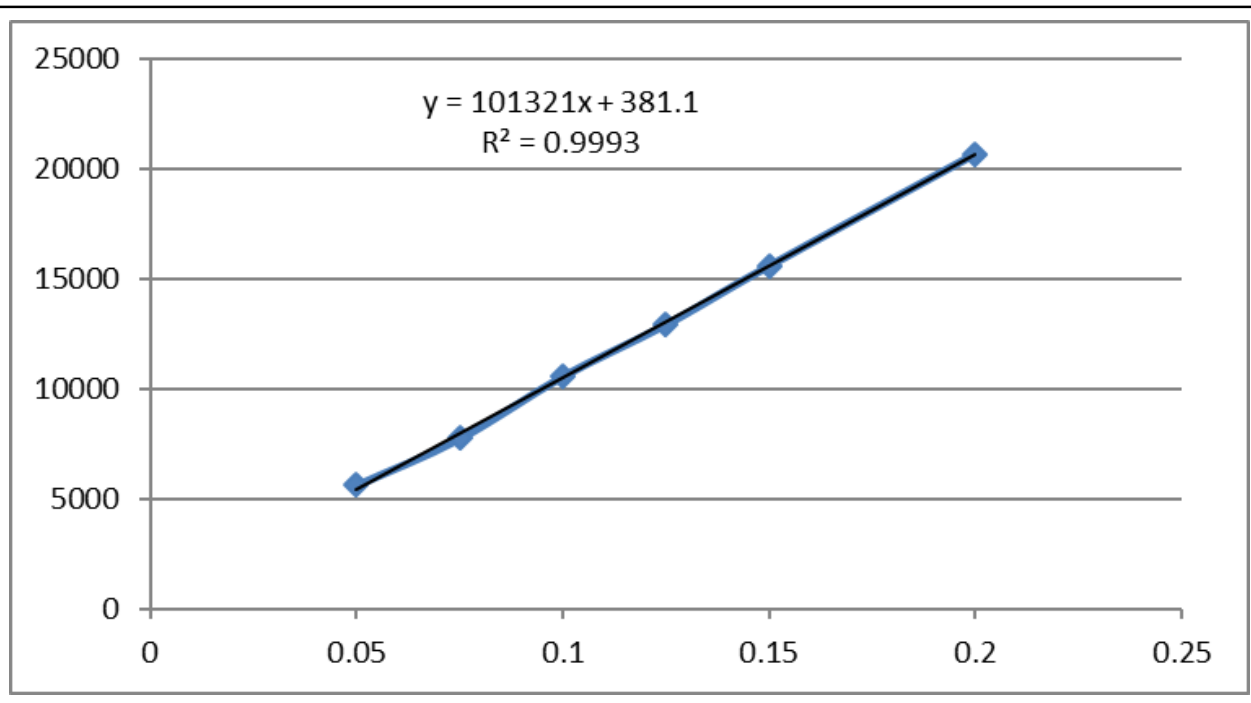

Fig.-4: Linearity Plot for EBS Standard from $0.05 \mu \mathrm{g} / \mathrm{mL}$ to $0.20 \mu \mathrm{g} / \mathrm{mL}$

\section{Accuracy}

The method accuracy was proved by showing recovery of EBS from Amlodipine drug peak. Satisfactory recoveries in the range of $98.1-103.0 \%$ for $0.05,0.10$ and $0.15(\mu \mathrm{g} / \mathrm{mL}$ ) (six determinations, $\%$ RSDs 1.28 1.96) were obtained which are satisfactory at such low levels. Corresponding data are represented in Table-3 and the LC-MS/MS SIM chromatograms of EBS for linearity study are shown in Fig.-5a to c.

\section{Quantification and Detection Limits}

LOQ value was assessed from the least EBS-concentration that produced $\mathrm{S} / \mathrm{N}$ ratio 10 and $\% \mathrm{RSD}<10$. LOD was established from the least EBS concentration that shows $\mathrm{S} / \mathrm{N}$ ratio 3. Signal to noise ratio data 
RASĀYAN J. Chem.

Vol. 13 | No. 3 |1662-1671| July - September | 2020

engendered from six repeated injections of EBS w. $r$. to test sample concentration $(10 \mathrm{mg} / \mathrm{mL})$. The derived LOD and LOQ values for EBS were $0.01 \mu \mathrm{g} / \mathrm{mL}$ and $0.04 \mu \mathrm{g} / \mathrm{mL}$ respectively and were embodied in Table-4 and Fig.-6a.

Table-3: Accuracy Results of Ethylbenzene Sulfonate

\begin{tabular}{|c|c|c|c|c|c|c|c|c|c|c|c|c|}
\hline $\begin{array}{l}\dot{z} \\
\dot{n}\end{array}$ & 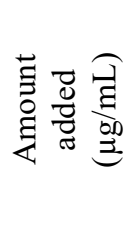 & 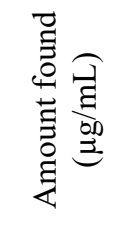 & 导 & 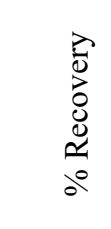 & 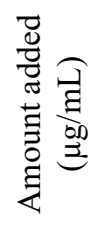 & 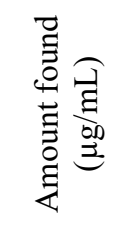 & 总 & 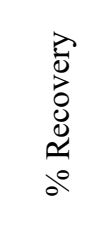 & 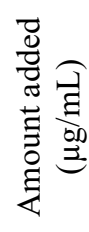 & 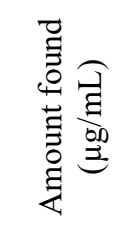 & 胥 & 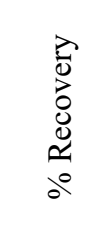 \\
\hline 1 & 0.05 & 0.0497 & 5597 & 99.4 & 0.1 & 0.0986 & 10436 & 98.6 & 0.15 & 0.1512 & 15731 & 100.8 \\
\hline 2 & 0.05 & 0.0494 & 5563 & 98.8 & 0.1 & 0.0981 & 10383 & 98.1 & 0.15 & 0.1506 & 15669 & 100.4 \\
\hline 3 & 0.05 & 0.0512 & 5766 & 102.4 & 0.1 & 0.1023 & 10828 & 102.3 & 0.15 & 0.1489 & 15492 & 99.3 \\
\hline 4 & 0.05 & 0.0493 & 5552 & 98.6 & 0.1 & 0.0984 & 10415 & 98.4 & 0.15 & 0.1519 & 15804 & 101.3 \\
\hline 5 & 0.05 & 0.0515 & 5799 & 103.0 & 0.1 & 0.1015 & 10743 & 101.5 & 0.15 & 0.1531 & 15929 & 102.1 \\
\hline 6 & 0.05 & \multirow[t]{5}{*}{0.0495} & 5574 & 99.0 & 0.1 & 0.0993 & 10510 & 99.3 & 0.15 & 0.1479 & 15388 & 98.6 \\
\hline \multicolumn{2}{|c|}{ Mean } & & & 100.2 & & & & 99.7 & & 100.4 \\
\hline \multirow{2}{*}{\multicolumn{2}{|c|}{$\begin{array}{l}\text { SD } \\
\text { RSD }\end{array}$}} & & & 1.964 & & & & 1.768 & & & & 1.289 \\
\hline & & & & 1.96 & & & & 1.77 & & & & 1.28 \\
\hline \multicolumn{2}{|c|}{$\operatorname{Conc}(\mu \mathrm{g} / \mathrm{mL})$} & & & 0.05 & & & & 0.10 & & & & 0.15 \\
\hline
\end{tabular}
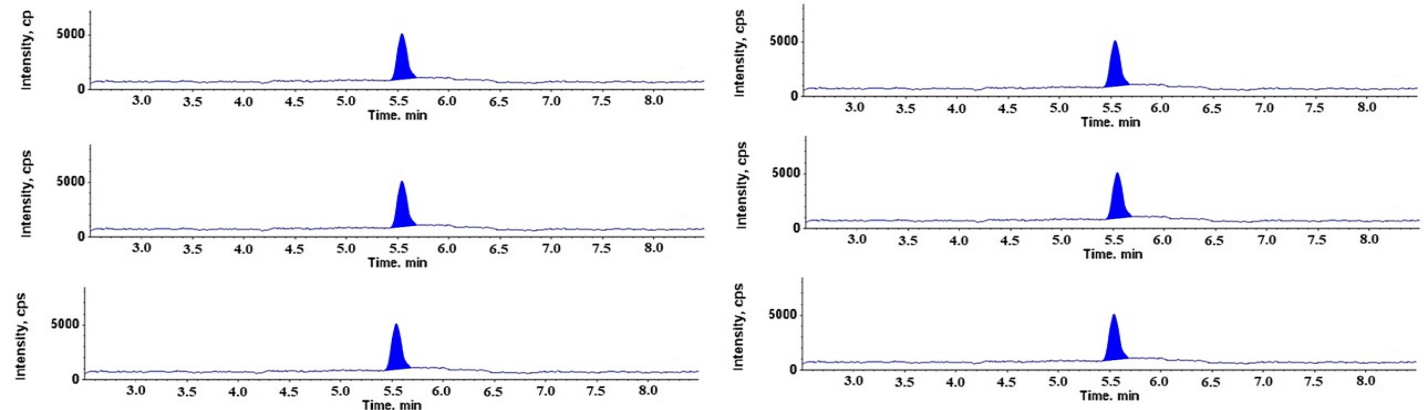

Fig.-5a: Accuracy at $0.050 \mu \mathrm{g} / \mathrm{mL}$
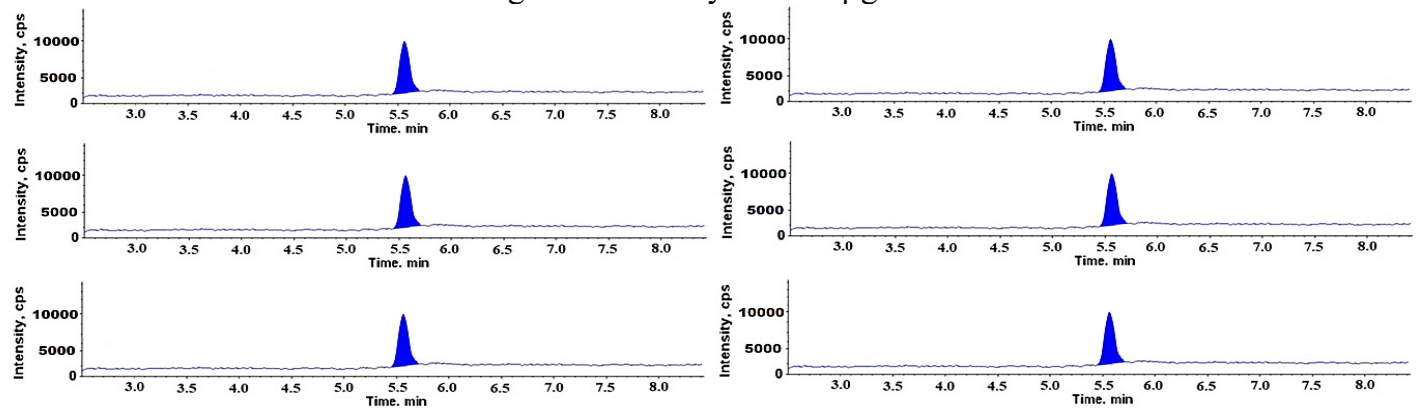

Fig.-5b: Accuracy at $0.10 \mu \mathrm{g} / \mathrm{mL}$
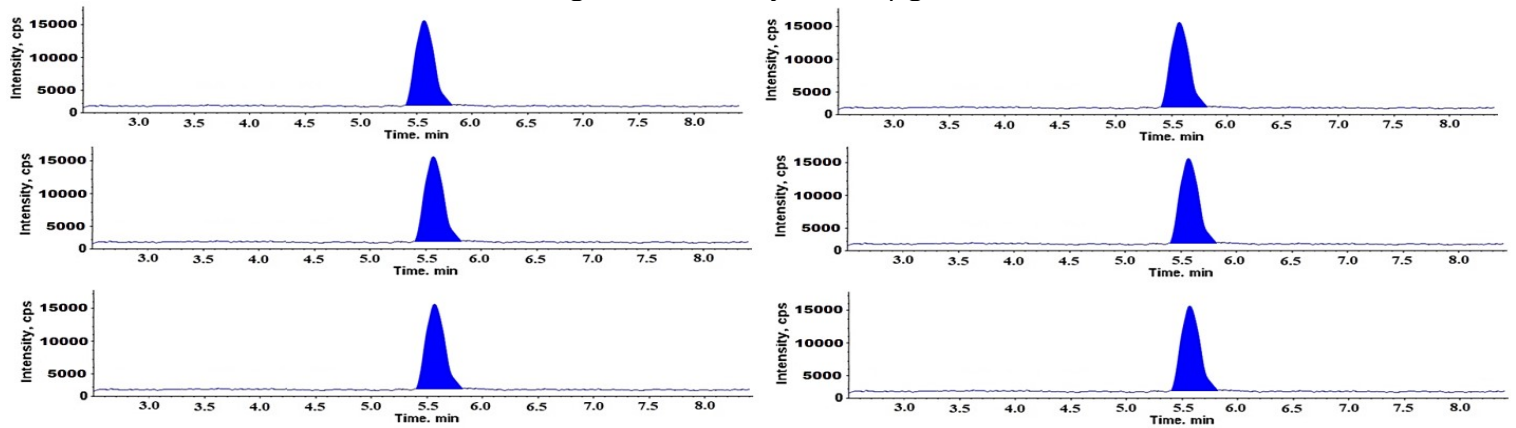

Fig.-5c: Accuracy at $0.150 \mu \mathrm{g} / \mathrm{mL}$ 
RASĀYAN J. Chem.

Vol. 13 | No. 3 |1662-1671| July - September | 2020
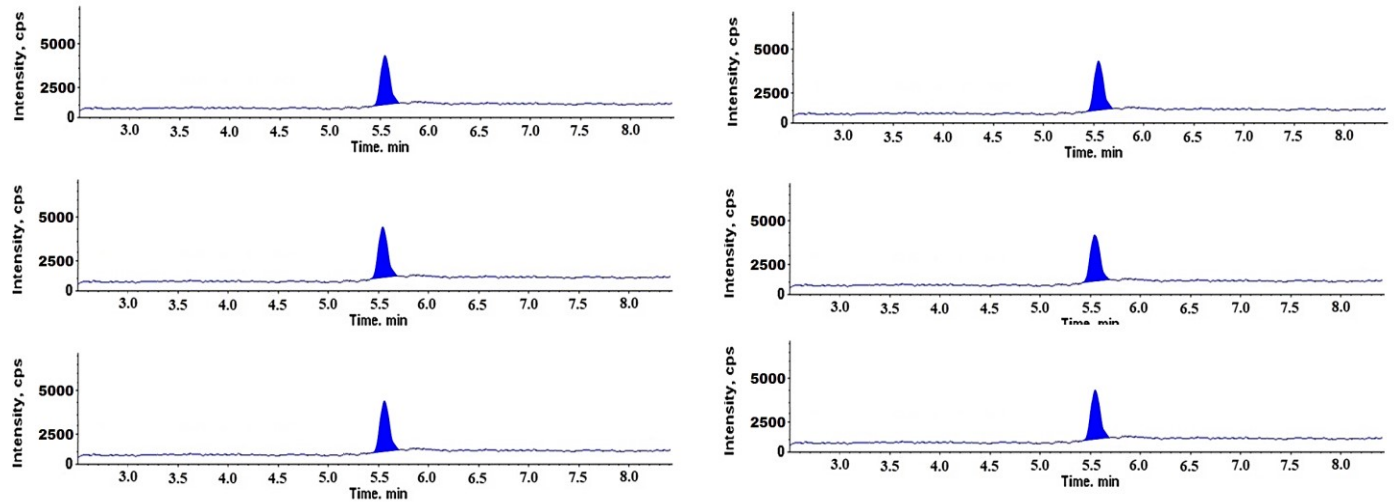

Fig.-6a: Chromatograms of LOQ Precision Study
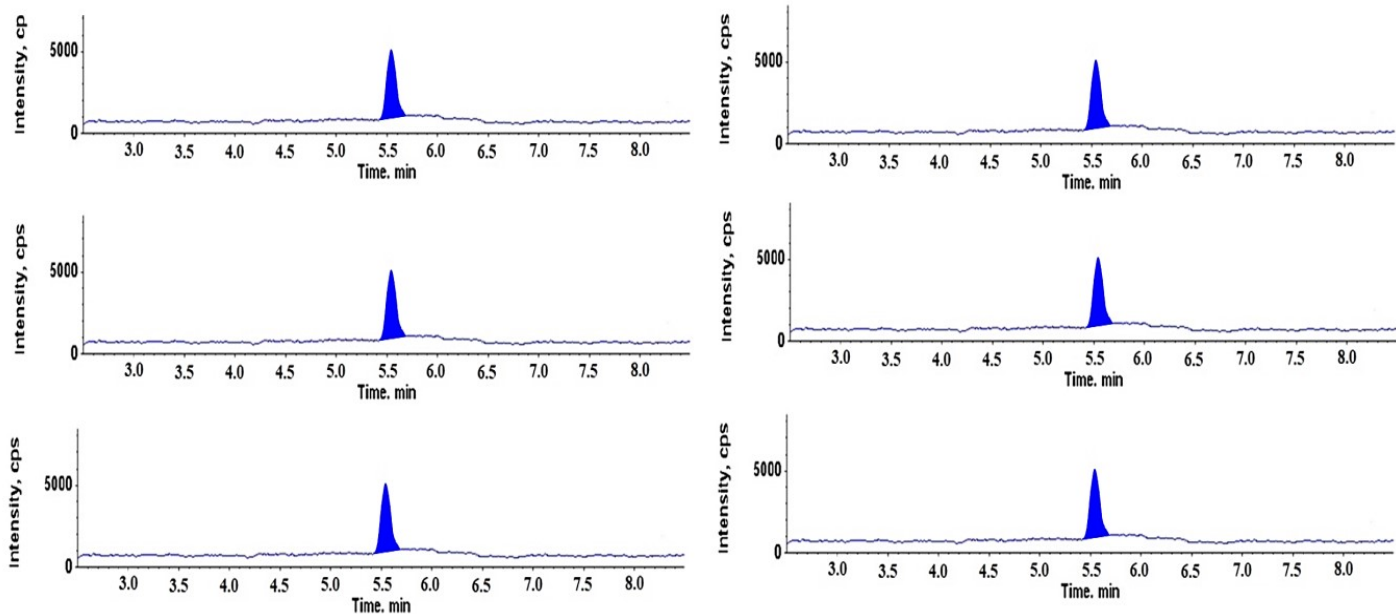

Fig.-6b: Chromatograms of System Precision Study
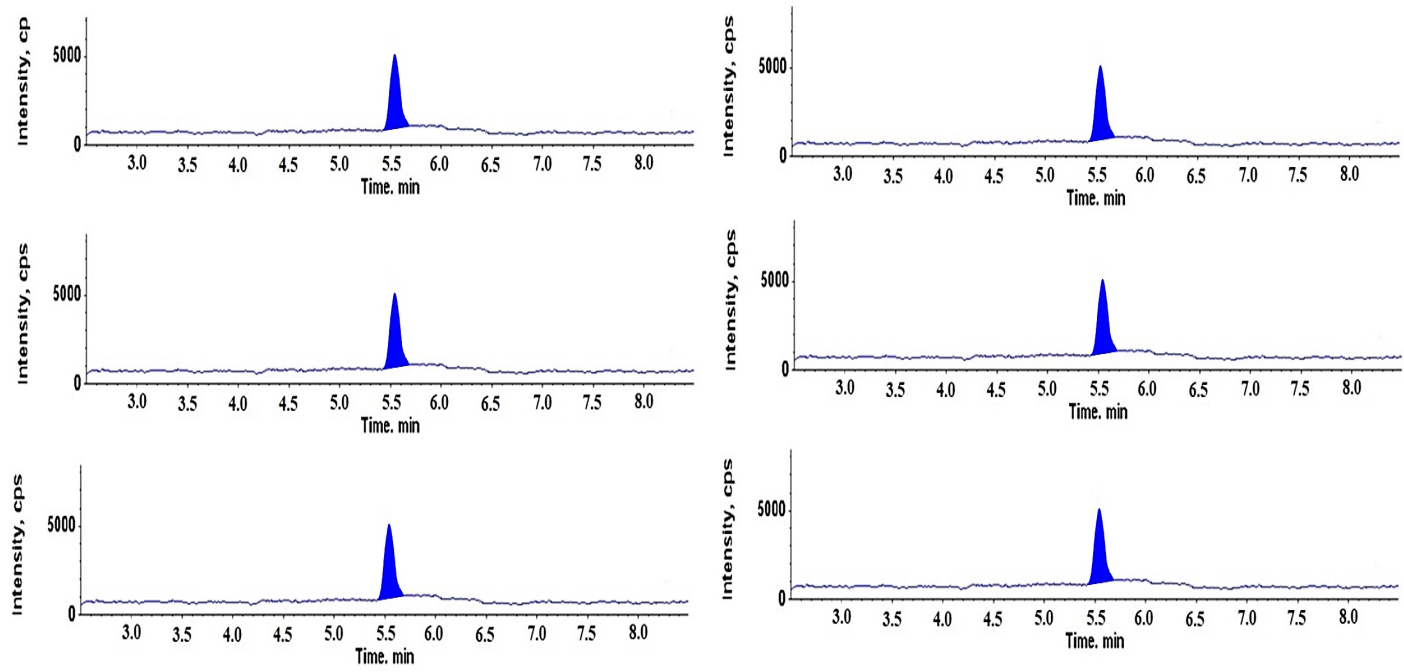

Fig.-6c: Chromatograms of Method Precision Study

\section{Precision}

The precision of the established method was evaluated by analyzing solutions at LOQ level six times and the data was depicted in Table-5. The RSD values were calculated from the areas of each EBS peak. The percent RSD was observed to be: $<3 \%$ for EBS in the parameter-system precision. Spectral data relating to precision study was depicted in Fig.-6b and 6c. 
RASĀYAN J. Chem.

Vol. 13 | No. 3 |1662-1671| July - September | 2020

Table-4: LOQ Precision and System Precision Results

\begin{tabular}{c|c|c}
\hline \multirow{2}{*}{$\begin{array}{c}\text { Injection } \\
\text { ID }\end{array}$} & LOQ Precision & System Precision \\
\cline { 2 - 3 } & $\begin{array}{c}\text { Area at LOQ } \\
\text { (Conc } 0.04 \mu \mathrm{g} / \mathrm{mL})\end{array}$ & Area at $0.05 \mu \mathrm{g} / \mathrm{mL}$ \\
\hline 1 & 4504 & 5543 \\
\hline 2 & 4523 & 5891 \\
\hline 3 & 4601 & 5672 \\
\hline 4 & 4489 & 5428 \\
\hline 5 & 4498 & 5783 \\
\hline 6 & 4598 & 5461 \\
\hline Mean & 4535.5 & 5629.67 \\
\hline SD & 46.39 & 168.44 \\
\hline$\%$ RSD & 1.02 & 2.99 \\
\hline \multicolumn{2}{c|}{$95 \%$ Confidence Interval } & \pm 102.5 \\
\hline
\end{tabular}

Table-5: Method for Precision Assessment

\begin{tabular}{c|r|c|c}
\hline \multirow{2}{*}{$\begin{array}{c}\text { Injection } \\
\text { ID }\end{array}$} & \multicolumn{3}{|c}{ Ethyl Benzene Sulfonate } \\
\cline { 2 - 2 } & Conc $(\mu \mathrm{g} / \mathrm{mL})$ & \multicolumn{2}{|c}{ Statistical Analysis } \\
\hline 1 & 0.0485 & Mean & 0.0485 \\
\hline 2 & 0.0465 & SD & 0.0012 \\
\hline 3 & 0.0491 & \% RD & 2.47 \\
\hline 4 & 0.0504 & \multirow{2}{*}{$95 \%$ Confidence interval } & \pm 0.005 \\
\hline 5 & 0.0478 & &
\end{tabular}

\section{Robustness}

The method robustness was ensured by varying flow of mobile-phase, the composition of organic solvent $\mathrm{A}$ and $\mathrm{B}$ and column temperature. Analyte and drug substances were always well resolved with a resolution of more than 2.0. The deliberate variation in mobile phase flow rate to an extent of \pm 0.2 $\mathrm{mL} / \mathrm{min}$; organic solvent $\mathrm{A}$ and $\mathrm{B}$ composition ratio to an extent of $\pm 2 \%$ and column temperature to an extent of $\pm 5^{\circ} \mathrm{C}$, were found to be not affect the separation.

\section{CONCLUSION}

The described mass spectroscopic method is a highly sensitive tandem mass method that can be used for both screening and quantification of Ethyl Benzene Sulfonate (EBS) in the Amlodipine Besylate drug substances. The developed method provides a high level of accuracy and detection limits due to reduced matrix effects of selected SIM ion mode. This method is a reliable and convenient tool for quality control due to its proven sensitivity and simplified testing sample solution preparation than the available methods for control of EBS in Amlodipine Besylate. This developed method can be utilized for the quantification of EBS on other drug substances.

\section{REFERENCES}

1. The Merck Index, An Encyclopedia of Chemicals, Drugs, and Biologicals, Fourteenth ed., Merck \& Co., Inc, Whitehouse Station, New Jersey, Monograph 491, 83(2006).

2. S. Goldmann, J. Stoltefuss, L. Born, Journal of Medicinal Chemistry, 35(18),3341(1992), DOI: $10.1021 / \mathrm{jm} 00096 \mathrm{a} 005$

3. H. P. Thacker, S-Amlodipine, Journal of Indian Medical Association, 105,180(2007).

4. D. Elder, K.L.Facchine, J.N. Levy, R. Parsons, D. Ridge, L. Semo, A. Teasdale, Organic Process Research \& Development, 16(11),1707(2012), DOI:10.1021/op300216x

5. European Directorate for Quality of Medicines and Healthcare, Enquiry: Alkyl Mesilate (Methanesulfonate) Impurities in Mesilate Salts, Pharm. Europa., 12 (2000).

6. Mesylate Ester Type Impurities Contained in Medicinal Products, Swissmedic Department for Control of the Medicinal Products Market: Berne, Switzerland, October 23 (2007). 
RASĀYAN J. Chem.

Vol. 13 | No. 3 |1662-1671| July - September | 2020

7. Guideline on the Limits of Genotoxic Impurities, Committee for Medicinal Products for Human Use (CHMP), European Medicines Agency (EMEA), CPMP/SWP/5199/02, EMEA/ CHMP/ QWP/ 251344/ 2006 (2006).

8. Genotoxic and Carcinogenic Impurities in Drug Substances and Products: Recommended Approaches, U.S. Department of Health and Human Services, Food and Drug AdministrationCDER, Silver Spring, MD-USA(2008).

9. R. Kroes, A.G. Renwick, M. Cheeseman, J. Kleiner, I. Mangelsdorf, A. Piersma, B. Schilter, J. Sclatter, F. Van Schothorst, J.G. Vos, G. Wurtzen, Food and Chemical Toxicology, 42(1), 65(2004), DOI:10.1016/j.fct.2003.08.006

10. International Conference on Harmonization of Technical Requirements for the Registration of Pharmaceuticals for Human Use (ICH), Guideline Q2(R1)-Validation of Analytical Procedures: Text and Methodology (2005).

11. M.Srinivasa Rao, S. Vinay Rao, K. P. Ramesh Babu, P. Satish Kumar, H. Kumar Sharma, Der Pharmacia Letter, 6(3), 47(2014).

[RJC-5819/2020] 